\title{
Development of Views on Science Questionnaire on the Basis of Experienced Scientific Knowledge, Atomic Model
}

\author{
An, Yu La $\cdot$ Shin, Ho-Sim $\cdot$ Kim, Hyun-Joo* \\ Korea National University of Education
}

\begin{abstract}
The objective of this study is developing an instrument for investigating views of the respondents on nature of science(NOS) by using experienced scientific knowledge, atomic model. It consists of total six questions and 36 detail items, and each question is reflected the aspects of different NOS which are 'recognition on the model', 'tentativeness of scientific knowledge', 'subjectivity in science', 'use of inference and imagination', 'myths of the scientific method', and 'comparison between science and art'. Particularly, 'comparison between science and art' is addressed almost for the first time in this questionnaire.

In the class environment almost not to teach nature of science linking with concrete scientific knowledge, to inquire how the students recognize nature of science, relating to experienced scientific knowledge through this questionnaire will give the data of scientific knowledge based recognition on the nature of science and an important implication for nature of science teaching with concrete scientific knowledge.

Developing processes have gone through four steps. In first step, we chose aspects of NOS and developed questions and details. In second step, we tested the draft into fifteen science teachers and, reflecting their opinions, corrected the form and contents of questionnaires. In third step, we tested the questionnaire included writing section for expressing thoughts of the respondents into 55 students in science high school and checked index of coincidence between Likert and open-ended responses which shows $88.2 \%$ degree of consensus. Furthermore, to identify the feature of using concrete scientific knowledge we applied this and views on science and education questionnaires together into six university students. We performed final test to 68 university students and measured Cronbach's , and ultimately completed final questionnaire in last step.
\end{abstract}

Key words: nature of science, development of a questionnaire, atomic model, science and art

\section{INTRODUCTION}

Understanding nature of science (NOS) is recognized as an important factor to acquire the scientific literacy (AAAS, 1989, 1993; NRC, 1996). Among the science philosophers, historians, scientists, and science educators, there are several differences of opinions in defining NOS specifically because it has complex and various features. However, some important issues on NOS accepted in general level have shared wisdoms without great disagreement (Abd-ElKhalick, Bell, \& Lederman, 1998). For example, scientific knowledge is tentative, subjective, theory laden, and partly and is a production of humans' inference, imagination, and creativity. In addition, there is no universal scientific method, and scientific model is accepted for explaining nature phenomena rather than trustworthy copies, and science has the aspect of creativity, construction. Most of these points of views are focused on recent science education revision document (AAAS, 1989, 1993; NRC, 1996; NSTA, 2000). Added to this, researches on similarities and differences of science and art constantly have been progressed in academy, and this recognition relates to profound understanding of NOS (Elgin, 2002; Hong, 2005; Miller, 1995; Stent, 2001). Despite of looking different, science and art have many similarities as human activity of creativity and this can be a new clue which shows us the respondents' view on NOS.

For decades, there were many research to

\footnotetext{
*Corresponding author: Kim, Hyun-Joo (hjkim21@knue.ac.kr)

**Received on 24 September 2011, Accepted on 10 May 2012

***This work was supported by the 2011 research grant from Korea National University of Education.
} 
understand students' and teachers' views on NOS(Akerson, Abd-El-Khalick, \& Lederman, 2000; Carey et al., 1989; Lederman et al., 2002; Solomon, Duveen, \& Scott, 1994) and some instruments were developed to investigate recognition of the teachers and students on NOS (Aikenhead, Fleming, \& Ryan, 1987; Billeh\&Hasan, 1975; Chen, 2006; Cooley \&Klopfer, 1963; Cotham\& Smith, 1981; Lederman et al., 2002; Lim et al., 2004; Meichtry, 1992; Soh et al., 1998; Welch \&Pelha, 1967-1968; Wilson, 1954). However, considerable numbers of these instruments have several problems in a developing process; i.e., 'subjects will recognize and interpret questions of an instrument like the way of the researchers' (Aikenhead, Ryan, \&Desautels, 1989; Lederman \& O’ Malley, 1990). Also, developers' viewpoint and prejudice has been reflected in these instruments because they were made in terms of specialists' position rather than that of respondents, and certain forms which force the respondents to choose brought the results to compel the viewpoint of the developer (Chen, 2006; Lederman, Farber, Abd-El-Khalick, \& Bell, 1998).

These problems partially were solved, so recently, most used instruments on NOS are Views of Nature of Science Questionnaire (VNOS) (Lederman et al., 2002) and View on Science-Technology-Society (VOSTS) (Aikenhead \& Ryan, 1992). VNOS is produced to aim to elucidate learners' NOS views and generate profiles of the meanings they ascribe to various NOS aspects for the purpose of informing teaching and learning of NOS (Lederman et al., 2002). Furthermore, VNOS was developed in A, $\mathrm{B}, \mathrm{C}, \mathrm{D}$, and $\mathrm{E}$ forms, and these have the form able to express respondents' opinions in writing down to all open-ended questions, and thereafter to carry out interview. For example, VNOS-C consists of 10 open-ended questions, and the respondents respond the questions for 45 60 minutes. However, the respondents feel difficulties expressing their thoughts on VNOS in writing. The students who are not good at explaining their opinions often describe in several words or sentences, or tend not to respond on certain questions (Liang et al., 2008). That is, there are great differences in quality and quantity of the responses as the respondents' depicting ability and inclination, excepting the recognition on NOS. Moreover, it is so difficult to acquire useful information from the contents of many depictions for the researchers (Chen, 2006) and needs skilled professionalism (Lederman et al., 2002).

VOSTS have been developed since 1987, for 6 years, and it is a representative instrument of examining NOS founded on many students' responses. It is also reflected on the students' thoughts as it is rather than presented right and wrong. Though, VOSTS brought each other's different interpretation between the respondents and researchers in interpreting questions like traditional NOS instruments (Chen, 2006), in multiple-choice format, only one example must be selected, so it cannot reflected on combinations of views of the respondents (AbdEl-Khalick\&BouJaoude, 1997; Mellado, 1997). According to several pre-researches, the respondents possess many philosophic viewpoints on NOS (Gallagher, 1991; Koulaidis \& Ogborn, 1989), and their viewpoints are not stable or sometimes, contradictable (Abd-ElKhalick\&BouJaoude, 1997; Mellado, 1997).

There is a recent developed instrument, Views on Science and Education Questionnaire (VOSE) (Chen, 2006) by compensating above stated the problems of VNOS and VOSTS. VOSE is developed to inquire the respondents' views on NOS and attitudes toward teaching science related them, and it consists of 15 questions. In addition, it reduces differences of interpretations between the respondents and developers by creating the items based on the respondents' point of view and taking five-point Likert scales, so it can measure confusing thoughts and took shorter time to respond (Chen, 2006). On the other hand, VOSE makes the respondents take a position, yes or no, and then, explain the reasons 
in Likert format, so the respondents should respond the reason of their objections, and it can make them somewhat be confused.

In addition, there is common problems with the existing NOS instruments; they contains general terms such as 'theory', 'law', 'scientific principle' and etc, but there can be the differences of interpretation between the researchers and respondents for them. In Paik's research (2006), it reported that the respondents interpret 'scientific theory' as 'scientific knowledge' or 'scientific principle'. The respondents do not grasp their accurate meanings, though they heard these general terms in many times, so there is a possibility of the difficulties on answering. Solomon et al.(1996) discovered, in the course of semistructured interviews, that many average level students feel difficulties to express their opinions with the expressions, 'experiment', 'theory', and 'scientific knowledge'. Therefore if concrete and experienced scientific examples met with far more comments are suggested, the respondents will easily and clearly understand the meanings of questions and researchers will obtain more exact views on NOS of respondents.

Among existing instruments, there is a case of using general terms with concrete examples in brackets such as "scientific theory (atomic theory, evolution theory etc.)' in questions, or some of the questions adapted concrete examples (Lederman et al., 2002; Lederman \& O’ Malley, 1990; Kang, Scharmann, \& Noh, 2005; Solomon et al.,1996). On the contrary, there is no try, all aspects of the instruments adapt to concrete scientific knowledge to inquire recognition on NOS. This try will not only induce the responses on NOS more easily but also be a great opportunity to understand how the recognition on NOS reveal relating to specific scientific knowledge, unable to approach with existing instruments. Therefore, in this research, by using concrete scientific knowledge, atomic model, we develop a practical and useful instrument to assessment views on NOS recognition of high school and university students, teachers, and the general public.

\section{DEVELOPMENT OF VIEWS ON SCIENCE QUESTIONNAIRE}

We used experienced scientific knowledge in development of questionnaire to identify recognition of the NOS unlike existing questionnaire used the general terms like 'scientific theory', 'scientific principle', and 'scientific fact'. AS the NOS are immanent in process creating scientific knowledge, learners might experience various views of NOS directly or indirectly in learning. Thus, we chose the atomic model' as high potential subject of these experiences and developed scientific knowledgebased questionnaire on NOS. However, use of concrete scientific knowledge give the limitation of targets of survey as who have learning experience of the knowledge and learning experience of targets is not sure their perfect knowing about the contents related the knowledge. Thus the knowledge based recognitions on NOS obtained by adapting this questionnaire do not premise respondents' perfect understanding of atomic model but just their learning experience.

The detailed reasons for choosing 'atomic model' are as follows.

'Atomic model' is treated in physics and chemistry textbooks of natural science field in almost high school. And most of the textbooks present transformation process of atomic model by reflecting on a historical background on atomic model instead of introducing each atomic model separately. It can help to learn various atomic models like Thomson's atomic model, Rutherford's, Bohr's, and orbital model, and a transformation process of them. Historical background and features of atomic model in textbooks closely relate to NOS as it is. For example, the transformation process of atomic model appeared in historical background relates to the tentativeness of scientific knowledge of 
NOS. Also, the drastic suggesting idea (Rodríguez \& Niaz, 2004), 'electron is a constituent atom', by measuring mass to charge ratio through cathode ray experiment, relates to "the necessity of imagination and inference in science.' For these reasons, we selected 'atomic model' as a familiar scientific knowledge example. Developing the questionnaire passed through four steps. In first step, considering relations to atomic model, aspects of NOS were selected. Questions and details were developed to lessons the differences of interpretations between the developers and respondents by referring to profile of previous research based on actual responses.

In second step, we tested developed version 1 questionnaire into 15 science teachers as quasiexpert group and completed version 2 questionnaire with the results.

Third, we putboth version 2 questionnaire and VOSE into 6 university students and surveyed the opinions through interview. And then, adding sections for writing the respondents' thoughts, we testedversion 2 questionnaire into 55 science-high school students. With the results, we identified how well this Likert-type questionnaire lead the respondents' opinions and calculated Cronbach's. According to analyzing interview and test results of science-high school, we edited it and made version 3. In second and third steps, we continuously tried to reduce the differences of interpretation between the developers and respondents on questionnaire items.

Finally, we tested questionnaire version 3 into 68 university students and analyzed materials to secure reliability and validity. Final questionnaire has 6 questions and each item consists of $5 \sim 7$ Likert-type details.

\section{NOS aspects}

After examining previous research on features of atomic model and historical background related to atomic model (Justi\& Gilbert, 2000;
Rodríguez \&Niaz, 2004), we chose suitable point of view for inducing recognition of the respondents on NOS. The viewpoint selected uppermost is "the recognition about model (Cha, Kim, \& Noh, 2004; Treagust, Chittleborough. \&Mamiala, 2002)', and it is thought most basic notion as property of basis of atomic model. Another viewpoints, selected in many previous research (AAAS, 1993; NRC, 1996; McComas\& Olson, 1998; Abd-El-Khalick, Bell, \& Lederman, 1998; Lederman, 1992; Chen, 2006; Lederman et al., 2002), are 'tentativeness of scientific knowledge', 'subjectivity in science', 'inference and imagination in doing science', and 'myth of the scientific methods'. Furthermore, in this questionnaire, including the viewpoint 'comparison between science and art', we tried to survey recognition of the respondents on aspect of creativity and construction, beauty like art. Below are some explanations on aspects of NOS chosen in developing questionnaire.

1) Scientific model Atomic model is a representative example of scientific model. Scientific model does not present an actual entity as it is or copies of reality. It is the constructed representations that may embody certain theoretical perspectives by reflecting on imagination and creativity of the scientists.

2) Tentativeness of scientific knowledge Scientific knowledge, though reliable and durable, is never absolute or certain and is subject to change. This change can appear because the existing theory is corrected by using new proof or by interpreting materials with new standpoint or perspective. Atomic model passed through from the ancient Greek to Dalton's model, Thomson's, Rutherford's, Bohr's, and orbital model. Although orbital model based on quantum mechanics, now, secure a solid position, but it also never acquire an absolutely proven status and are subject to change.

3) Subjectivity in science Scientists' faith, background knowledge, training, experience, and expectation practically affects on their study. These factors influence on how the 
scientists perform their research, what they observe, how they interpret the phenomena. Among historical backgrounds of atomic model, Thomson and Rutherford's story, they differently interpreted the result of particle scattering experiment each other, is a good example of subjectivity in science.

4) Use of inference and imagination Partly, scientific knowledge is a production of human inference, imagination, and creativity. Science includes inventions of theoretical entities needed lots of creativity. Scientific entities, such as atom or electron and etc, are theoretical models based on the scientists' inference and imagination rather than believable copies of reality. The historical story related to discovery of electron by Thomson is a good example of using inference and imagination in science.

5) Myth of the scientific methods One of the most common myths of the scientific method is the existence of 'universal scientific method'. Namely, people believe scientists carry out the research by inquiry processes like a recipe by stages. However, there is no 'scientific method' which guarantees conclusive scientific knowledge (Bauer, 1994; Lederman et al., 1998; Shapin, 1996). Depending on the circumstances the scientists just design and perform activities such as observing, comparing, measuring, testing, speculating, making hypothesize, creating ideas and conceptual tools, and constructing theory and explanation. Thomson, Rutherford, and Bohr also did not follow universal scientific method and carried out research with their own suitable method.

6) Comparison between science and art Scientific creativity and artistic creativity are very similar, and like art, science emphasizes on imagination, intuition, and visualization (Hong, 2005; Kim, 1995; Miller, 1995). A science activity has aspect of not discovering the facts and rules in nature but inventing and construction. Besides, both science and art have the aspect of aesthetics (Engler, 1990; Miller, 1995). Of course, there is a difference between the beauty of art and that of science, but definitely, the scientists pursue the aspect of aesthetics as simplicity, symmetry, and etc. Both studies are processes of constructing the world by using human sensation and reason, and of understanding, interpreting, and these complex processes cannot describe with dichotomous category like subjectivity-objectivity or sensation-reason (Feyerabend, 1994; Hong, 2005; Van Frassen, 1994).

\section{Developing Items}

Prior to develop items, we examined profiles of the respondents presented in VNOS and previous researches (Aikenhead, Fleming, \& Ryan, 1987; Aikenhead\& Ryan, 1992; Chen, 2006; Liang et al., 2008). In addition, we examined the studies on atomic model (Justi\& Gilbert, 2000; Rodríguez \& Niaz, 2004), on model (Cha, Kim, \& Noh, 2004; Treagust, Chittleborough, \&Mamiala, 2002) and science and art (Clarke \& Henderson, 2002; Elgin, 2002; Engler, 1990; Miller, 1995; Lynch \&Woolgar, 1990; Hong, 2005; Kim, 1995). From these processes, we make out a draft of questions and items on NOS by using atomic model examples. Total number of questions is six, and each question includes several detail items. The questions and items are presented in appendix, and below are detailed descriptions for aspects of NOS in parts of questions.

Question 3 is based on the example of 'subjectivity in science' in historical background on atomic model. After presenting the result of the Rutherford's $\alpha$ particle scattering experiment, Thomson and his colleagues also started to study $\alpha$ particle scattering in their laboratory. Though all results were similar, the interpretation of Thomson and Rutherford were totally different. Thomson suggested the hypothesis, compound scattering, and angle bias of $\alpha$ participle is caused by successful collision among participles, so positive charge $(+)$ is distributed in all over the atom. On the other hand, Rutherford proposed single scattering hypothesis and 
thought angle bias is a result of single collision between $\alpha$ participle and positive charge $(+)$ included in the nucleus. Rutherford's single scattering hypothesis founded on single collision and Thomson's compound scattering hypothesis lead ultimately intense arguments (Rodríguez \& Niaz, 2004). Like this, with the same experiment results, two scientists suggested their own atomic model through each different interpretation.

These results are caused by Thomson's and Rutherford's belief, background knowledge and expectation by their experiences or experiments and are a good example of subjectivity in science. Therefore, we presents the fact that Thomson and Rutherford acquired similar results of $\alpha$ particle scattering experiment and ask whether they can explain the same experimental results with each different atomic model in this question.

Detail items 1 and 2 revealed the position unable to explain with each different atomic model, but their reasons are different.

Detail 3 5 were developed based on interview materials of VNOS (Lederman et al., 2002) and statements emerged from the recent literature (Aikenhead\& Ryan, 1992; Chen, 2006) on subjectivity in science. All these items explain that each different atomic model can be presented, but the reason is not same.

Question 5 relates to "myth of the scientific method' which is one of the most common myths in science, the belief of existing universal scientific method. Related to this, looking into existing questionnaire, the term, universal scientific method is used in question. However, using this term tends to make the respondents, without their intentions, suppose the existence of universal scientific method or recognize the possibility of the existence of that. Therefore, in this question, 'How do scientists research?'. And in details 1, 2, by stating yes or no about presence of universal scientific methods, we intend to reveal the respondents' positions clearly. And then Thomson, Rutherford, and
Bohr proposed their own atomic model after many research processes. "How did Thomson, Rutherford, and Bohr research in this process?' .

Question 6 was developed to inquire recognition on NOS by "comparing science and art." In this question, by comparing similarity and differences of various parts such as common myth on science and art, experiencing NOS unlike art, creativity of science and art, constructive aspect as human acts, and aesthetic aspect, we intended to look into the views of the respondents on science. As one example of scientific knowledge and visual art, Bohr's atomic model and Picasso' s work are chosen, and with these examples, questions and details were developed.

Detail 1 presents common myth on science and art. That is, it showed wrong recognition that science deals with external reality and rules of nature, and the scientists just discover reality and rules, but art inquires human internal nature so is an activity of creating and constructing aesthetic values. This statement not only expresses oversimplified property of science and art but also does not consider the aspect of creation and construction on science. Scientists construct scientific knowledge by interpreting and studying several resources with many ways in social and cultural situation rather than simply discover (Hong, 2005).

Detail 2 presents the differences between science and art, and empirical NOS. Science, unlike art, is lead by observation of nature, and usefulness of scientific theory and knowledge is needed to support through empirical observation, experiments, or proofs (Abd-ElKhalick, Bell, \& Lederman, 1998).

Detail 3 is an item about creativity and imagination of science and art. Imagination and creativity play an important role in science activities similar to art activities (Hong, 2005; Kim, 1995; Miller, 1995). For instance, what scientist made theoretical entities such as atom or electron, and more specifically, in Bohr's atomic model, the ideas of specific orbit, energy 
level, and shift of electron to specific orbit are the parts needed awesome imagination (Lederman et al., 2002).

Detail 4 is a standpoint that both science and art are products of human spirit for explaining nature world and interpreting with given resources. Surely, science and art explain and interpret nature in different ways, but it is made and constructed by human.

Detail 5 relates to detail 1 and is based on the research of Stent who is molecular biologist (Stent, 1982). Stent found the stereotype that any biologists, instead of James Watson and Francis Crick, can discover DNA's double helix, but Shakespeare is the only person who can write Othello. This finding means many people, even scientists, recognize science is a discovery of objective reality or facts, but art is a construction of subjective nature. So, we will check inherent thinking of the respondents by adapting this result into Bohr's atomic model and Picasso' s work.

Detail 6 is an item of the beauty of science and art. Although, the beauty of science and that of art is not identical, science obviously pursues beauty, and many scientists also thought this aesthetic aspect importantly. For example, Hans Albert Einstein, the son of Albert Einstein, recalled whenever Einstein evaluated the theory, he gave more weighting to whether the theory was beautiful or not rather than the theory was right or wrong (Chandrasekhar, 1979). Furthermore, Rosalind Franklin who critically contributed to discover DNA structure said, "after finding DNA' s double helix, I cannot help accepting the result, DNA's double helix because it is very beautiful for denying" (McAllister, 1996).

Besides, the form of this questionnaire was discussed. On one occasion, Aikenhead (1988) did research on ambiguity of language by 4 different response types, Likert-type, written paragraph, semi-structured interview, and empirically derived multiple questionnaires. He pointed out each form's problems and said that empirical derived multiple-choice responses could reduce ambiguity of language. But, multiple-choice form has shortcoming, not measuring the respondents' combination of views and confused recognition. So, to correct the flaw, Liang et al.(2005) followed empirically derived Likerttype in developing Student Understanding of Scientific Inquiry (SUSI), the ambiguity of SUSI was $15 \%$ 20\%, so it is similar level to Aikenhead(1988)' s empirical derived multiple choice type.For this reason, we took Likert scales in this research to measure the respondents' combination of views. To reduce ambiguity of language, we finally selected empirical derived Likert scales, considering previous researches and materials. They consisted of five scales: Strongly disagree, disagree, neither agree nor disagree, agree, and strongly agree. VOSE also took Likert scales and has the form that each item is divided yes and no, and then, the reason was written. It may make respondents feel uneasy. So, we developed detail items as one simple sentence to reduce the confuse of respondents, because they choose yes or no beforehand, and then they are forced to respond even about inconsistent position.

\section{Preparative test}

We test the draft of this questionnaire on 15 middle and high school science teachers who majored in physics education. They learned atomic model in detail through modern physics class, and NOS through classes of science education. And, now, they have studying for a master's degree. They read intensively it and pointed out some problems - whether the meaning of questions or detail items is clear or not, Likert-criterion has ambiguous selection and difficulty or not, and grammatical error is included or not. With their advice we edited the questionnaire to clear meaning of questions and details. For instance, in case of question 3, we added more detailed explanation to make obviously. The reason is that Korea science curriculum for high school and university 
students includes only Rutherford's $\alpha$ participle scattering experiment without Thomson's experiment, so, we provided summative explanation about historical background of atomic model for the respondents to understand sufficiently.

Detail 1 and 2 of question 2 related to tentativeness of orbital model presented order effect through Likert-response and interview result of respondents. So, by changing the order of detail 1 and 2 each other, the content became to correspond to the respondents' opinions. Furthermore, we upgraded terms and sentences to clarify each item's meaning and deleted the item not revealed meaningful difference among detail items. Through this process, 3 questions were corrected, 7 detail items were deleted, 5 details were improved, and 1 detail was added. Finally, version 2 questionnaire was completed.

\section{Comparison of this questionnaire and VOSE}

We input version 2 questionnaire and VOSE to 6 students who major in physics education, and after responding, interviewed them. With this process, we compared VOSE and this questionnaire adapted concrete scientific knowledge, atomic model, and wanted to know the part needed to correct. The reason we chose VOSE is that it is similar to our questionnaire in form and suitable for comparing because it details in largely aspects of common NOS, and it was developed recently.

Each participant should respond common and individualized interview question respectively. Common questions are: "is there similarity or difference in form or content of two questionnaires? , 'what difference do you have in process of responding or thinking about two questionnaires? , 'is there difficulty in responding to this questionnaire?', 'please speak if you felt the questionnaire needs correction.' And considering participants' responses, there were additional questions. After constructing interview question, every participant carried out interview individually. We promoted comfortable atmosphere and provided enough time to explain simple response and its reason, and gave the chance for clarifying responses for all participants. This process enables us to approach the reason in not researcher's position but that of participant. Each interview progressed for 1 hour, and all interviews were recorded and transcribed as analyzing materials. With interview transcribing materials, we found common opinions of participants.

Participants presented opinions about similarities and differences in variable aspects such as contents, level of difficulty, interest, and expressions of their own opinions. In aspect of contents of two questionnaires, half participants responded they are similar in that two questionnaire include ultimate questions, approaching to recognition of respondents on NOS. Though this similarity, most of the participants pointed out patent difference. To put it another way, VOSE is rather abstract and general, but this questionnaire is concrete with example of atomic model. Thus, most respondents cognized fully the characteristic of this developed questionnaire.

Another salient difference is in relation to level of difficulty of response, and this questionnaire is easy to respond rather than VOSE. All participants (100\%) responded commonly, so we added additional questions, "What is the reason this questionnaire is easy to respond rather than VOSE?" or "why VOSE is more difficult to respond than this questionnaire?" Main reason $(83 \%)$ is in case of VOSE, because it asks overall science extensively, respondent might think in many ways, depending upon the type of research or situation. On the other hand, in case of this questionnaire, they can respond or think easily because concrete situation learned already is given.

Also, participants (67\%) uttered the difficulty of general terms such as scientific theory or law in VOSE. They heard and use the words like theory and law, but their meaning are not 
clearly established, so they feel difficulty in responding. In fact, in question "Is atomic model scientific theory?" "What is the example of scientific theory?", respondents are confused the terms like scientific theory and law, nature phenomena, and technology and invention. Paik (2006) pointed out that generally, in science textbooks or class, terms like scientific theory, scientific law, hypothesis, and scientific fact are used indiscriminately. This problem can make big obstacles in process of inquiring recognition of respondents by using general terms like existing questionnaires. A half of respondents answered, in a question related to 'scientific theory,' by associating with not scientific theory but scientific phenomenon ( the object falls down.') or scientific law ( $\mathrm{F}=\mathrm{ma})$. If you examine only responses and classify the opinions of the respondents on the scientific theory, not considering what they associate with, this will give wrong information. On the contrary, in case of this questionnaire used familiar scientific knowledge, interpretation of questions and terms is easier, the differences of interpreting questions between the respondents and researchers reduce, and the respondents can answer the questions with comfortable feeling.

Third reason (50\%) relates the form of VOSE. They say, the form of VOSE, choosing 'Yes or No' and then stating the reason, is considerably difficult. We concerned this problem; the respondents are forced to answer in opposite position, in developing items of this research. Through this process, we concluded as a method of reducing confusion of the respondents by developing detail items of questionnaire with one single sentence.

There were students who answered this questionnaire is more interesting than VOSE. The reason is it is based on familiar examples, it gives more practical feeling, and 'personal preference.' 4 students of 5 mentioned this questionnaire showed their own opinions more clear. Its reason is that this questionnaire presents concrete examples, so it is relatively easy to think and gives the chance of thinking several times.

In addition, this questionnaire has unity among the questions and gives a flow of story consistently presenting contents of atomic models, so they became to expect next contents unlike unfriendly and abstract VOSE.

\section{Pilot test of students in science high school}

For securing reliability of this questionnaire, we added open-ended questions related to questions of version 2 questionnaire and put it into 55 students in science-high school. We checked index of coincidence between Likert and open-ended responses, and with result of Likert responses, we calculated Cronbach's $\alpha$ to obtain internal consistency reliability. Analyzing processes and methods are below.

\section{Calculating index of coincidence between Likert and open-ended responses}

First of all, we tried to survey how much did Likert responses accord with students' thoughts. So, we corrected some part of the version 2 questionnaire, and then, the students can answer to details questions formed Likert-type and write their own opinions in below section, open-ended question. For example, in case of questions 2 related to tentativeness of scientific knowledge, we gave following questions: 'Do you think orbital model can be changed in the future? Write down full reasons why you think so.' 'If you think orbital model will be changed, what is the cause of change? Most students answered sincerely both types of questions, but only 1 student kept the same score to all Likert questions and did not do any open-ended questions, so he was excluded in analyzing. Responses of 54 students were analyzed for checking index of coincidence as follows.

In Likert responses, we gave score from 0 , 'Strongly disagree' to 4 score, 'Strongly agree' for positive items and inversely for negative 
items. Each question's score is average score of detail items.

In case of open- ended questions, 3 researchers made common criteria of grade on each question and analyzed respectively. The grade of openended question is fixed from 0 point to 4 , leaving spaces of 0.5 point like a grade of Likert-type response.

For example, items of question 1 includes the contents whether atomic model presents an actual entity as it is or not and whether atomic model reflects the creativity and imagination of the scientists, what the objective of making atomic model is. Below presented open-ended question is what do you think of atomic model? (Please write concretely on the relevance between atomic model and real entity and the reason the scientists research atomic model.)' We decided the scoring criteria to evaluate the quality of respondents' view. Table 1 represents the example of criteria for grading the response of open-ended question 1.

With this method, the standard of grade of other questions is set. Also, according to this criterion, we gave marks on 54 students' responses respectively. The grade averagely showed 80\% degree of consensus. For the part of disagreement, we discussed and gave the scores together.

We introduce the index of coincidence to check the consensus between Likert and open-ended responses. Index of coincidence of question i of the $\mathrm{j}$ student is $A_{i j}=\left(1-\frac{1}{4}\left|R_{i j}-W_{i j}\right|\right) \times 100$. Index of coincidence of question i of total students is $A_{i}=\frac{1}{N} \sum_{i=1}^{N} A_{i j} R_{i j}$. presentsLikert score of question $\mathrm{i}$ of the $\mathrm{j}$ student, $W_{i j}$ is the score of open-ended question $\mathrm{i}$ of the $\mathrm{j}$ student, and Nis total number of students. Table2 shows index of coincidence of each question.

Index of coincidence of each question appears from $84.0 \%$ to $91.6 \%$, and average index of coincidence is $88.2 \%$. The result indicates that the empirical Likert scale questionnaire lead to the students' views on NOS properly.

According to the Likert-results of 54 students in science high school, we obtained for Cronbach's $\alpha$ of each question. Cronbach's $\alpha$ becomes not a main standard of choosing items or a criterion of evaluating reliability but a tool for inquiring range of meaningful reliability and

\section{Table 1}

The criteria of score for open-ended question 1

\begin{tabular}{cl}
\hline \hline Score & \multicolumn{1}{c}{ The criteria of response of open-ended type question } \\
\hline & Atomic model does not present an actual entity as it is. \\
Atomic model does not represent a similar thing to actual atom. & $\begin{array}{l}\text { Atomic model was made by reflecting on imagination and creativity of the scientists. } \\
\text { Atomic model is to explain the experiment or phenomena related to atomic structure. } \\
\text { The case of including above } 4 \text { statements. }\end{array}$ \\
\hline 3.5 & The case of including above 3 statements. \\
\hline 3 & The case of including above 2 statements. \\
\hline 2.5 & The case of including above 1 statement. \\
\hline 1.5 & $\begin{array}{l}\text { Neutral position, no-answer, ignorance, the case it is hard to judge with statement about } \\
\text { above } 4 \text { factors, inconsistency. }\end{array}$ \\
\hline 1 & (Without direct expression) the case of regarding atomic model as an actual entity indirectly. \\
\hline 0.5 & The case of presenting atomic model as an actual entity. \\
\hline & $\begin{array}{l}\text { Recognizing atomic model as an actual entity, including } 2 \text { statements of below } 3 \text { factors. } \\
\text { In atomic model, there is not imagination or creativity of the scientists. }\end{array}$ \\
& $\begin{array}{l}\text { Atomic model has the objectivity of expressing an actual entity. } \\
\text { Including all above } 3 \text { statements. }\end{array}$ \\
\hline
\end{tabular}


Table 2

Index of coincidence of each question

\begin{tabular}{ccc}
\hline \hline Question & NOS & Index of coincidence $A_{i}(\%)$ \\
\hline 1 & Recognition on model & 84.0 \\
\hline 2 & The tentativeness of science knowledge & 90.1 \\
\hline 3 & The subjectivity in science & 88.6 \\
\hline 4 & The use of inference and imagination in science & 91.6 \\
\hline 5 & Myth of the scientific methods & 88.4 \\
\hline 6 & Comparison between science and art & 86.5 \\
\hline total & & 88.2 \\
\hline
\end{tabular}

figuring out the part needed correction because traditional reliability and validity should not be adapted for empirical developed tools (Aikenhead\& Ryan, 1992; Rubba, Schoneweg Bradford, \&Harkness, 1996). Table 3 reveals Cronbach's $\alpha$ result of each question.

Each Cronbach's $\alpha$ of each question is 0.38 to 0.67 in this test. This Cronbach's $\alpha$ was used to search for details which drop reliability, to examine, improve, and delete. So, 4 items were deleted. For example, a item of question 3 related to subjectivity in science had low consistency, so we excluded it, and thereafter, Cronbach's $\alpha$ increased to 0.56. And, Cronbach's $\alpha$ of question 6 was 0.18 , very low figure because similar statements of 2 items caused this result. Therefore we deleted one of them and gained numerical value 0.38 .

With interview materials of 6 university students and pre-test results of 54 science-high school students, we completed version 3 , which consists of total 6 questions and 36 detail items.

\section{Final test of university students}

We tested version 3 questionnaire into 68 students in university of education in Korea. They major in physics education, chemistry education, and biology education, most of whom learned atomic model in science curriculum of high school or university. They answered for 10 15 minutes, and through the result, we calculated Cronbach's $\alpha$ of final test. Table 4 presented in the result.

Cronbach's $\alpha$ of each question in final test ranges from 0.36 to 0.72 . Comparing these figures to version 2 , they were much alike or increased in all questions and for the most questions Cronbach's $\alpha$ were obtained larger values than 0.6 that means this questionnaire have meaningful reliability. The lowest figure appeared in question 6 like version 2. In case of question 6 , the objective is inquiring recognition based on comparison between science and art, somewhat extensive content, so it has low consistency among the questions and showed

\section{Table 3}

Cronbach's $\alpha$ of version 2

\begin{tabular}{ccccccc}
\hline \hline Question & 1 & 2 & 3 & 4 & 5 & 6 \\
\hline Cronbach's $\alpha$ & 0.46 & 0.59 & 0.56 & 0.59 & 0.67 & 0.38 \\
\hline
\end{tabular}

\section{Table 4}

Cronbach's of version 3

\begin{tabular}{ccccccc}
\hline \hline Question & 1 & 2 & 3 & 4 & 5 & 6 \\
\hline Cronbach's $\alpha$ & 0.63 & 0.61 & 0.72 & 0.58 & 0.61 & 0.36 \\
\hline
\end{tabular}


low Cronbach's $\alpha$ figure. Cronbach's $\alpha$ is coefficient for measuring consistency among many detail items of one concept, and the narrower and more concrete of the concept, the bigger figure tends to be calculated. However, empirically created tools were developed by quality viewpoint, so it is proper to focus on quality and meaning of the question by researchers' sincerity and variable sources rather internal consistency of traditional viewpoint (Aikenhead\& Ryan, 1992; Creswell, 1994). Completed questionnaire consists of 6 questions which reflect different viewpoints of NOS and 36 items of every question. Final questionnaires are presented in appendix.

\section{Conclusion and Implications}

In this study, using the concrete and experienced scientific knowledge of atomic model, the questionnaire was developed to assess respondents' view on NOS. This tool is for the general public, including high school students, university students and teachers who learned atomic model. It consists of total 6 questions and 36 detail items, and each question is reflected different aspects of NOS. Selected NOS in this research is 'recognition on the model', 'tentativeness of scientific knowledge', 'subjectivity in science', ' use of inference and imagination ', 'myths of the scientific method', and 'comparison between science and art.' Considering shortcoming of traditional questionnaires such as VNOS, VOSTS and VOSE, we improved the form and content of questionnaires in this research. This questionnaire was developed with empirical viewpoint, so that is why its reliability depends on methodological technique and researcher' s sincerity, and to increase internal reliability, various source and researchers' triangulation are essential. Therefore, in developing this questionnaire, we diversified sources of information such as making items based empirical previous research, pre-test of science teachers, checking index of coincidence between Likert and open-ended responses of science high school students, comparing existing questionnaire and this questionnaire through interview materials of university students. Likert-type is used in aspect of form, it is possible to measure some confused viewpoint of the respondents. Moreover, response time is relatively short, 10 15 minutes and it can be the merits in future usage.

The most distinctive characteristics of this questionnaire in comparison with the existing is that this questionnaire could be presenting scientific knowledge-based recognition of NOS. Although we do not confirm how degree respondents understand about contents of the knowledge, we expect that learning experience for such knowledge can just reduce difficulties of response and help respondents presenting knowledge-based recognition of NOS. Actually, we compared the responses of VOSE with those of this questionnaire and found while the respondents feel confusion and difficulty of general terms used in VOSE, more effectively revealed their opinions for this questionnaire.

Moreover, this questionnaire introduced the viewpoint, 'comparison between science and art' rarely dealt with and presented internal thoughts on various aspects like general myths of science and art, empirical NOS unlike art, creativity of science and art, constructional aspect as human action, aesthesis.

The feature of this questionnaire, which is based on scientific knowledge, is the limitation as well as advantage. When you survey overall recognition on NOS, it gives one reference data, but because of its feature, more studies must be done for a broad interpretation from single scientific knowledge of atomic model toward overall recognition. Nonetheless, investigating how the respondents think viewpoint of NOS in relating to concrete scientific knowledge is very critical in that NOS ought to be taught with scientific knowledge in science class. Put in another way, this questionnaire gives the 
opportunity of appreciating how NOS could be adapted and understood to concrete scientific knowledge, a guideline for adapting and connecting NOS with concrete curriculum contents in science class. This information provides not only teachers but curriculum developers, textbook authors, and educational policy makers with many implications.

In the future, more detailed researches on differences of responses between this questionnaires based on concrete scientific knowledge and general NOS questionnaires are required. If, a respondent who appeared high recognition in general NOS questionnaire but revealed low recognition in this questionnaire, it perhaps means overall recognition on NOS cannot be adapted to concrete scientific knowledge. On the contrary, if the opposite case appears, we have to research the cause of this difference more profoundly, not judging his recognition as low level. Added to this, further studies on the case of adapting other scientific knowledge besides atomic model are also need. Continuing studies on the similarity and difference between questionnaires based on concrete scientific knowledge and general questionnaire will allow inquiring the clear and meaningful conceptions of NOS of respondents and giving a guide teaching NOS.

We reported the results of understanding on NOS of pre-service secondary science teachers using this questionnaire and comparisons with pre-studies using the NOS instruments contains general terms in other paper (An \& Kim, 2011)

\section{Reference}

Abd-El-Khalick, F., Bell, R. L., \& Lederman, N. G. (1998). The NOS and instructional practice: Making the unnatural natural. Science Education, 82, 417-436.

Abd-El-Khalick, F., \&BouJaoude, S. (1997).An exploratory study of the knowledge base for science teaching.Journal of Research in Science Teaching. 34, 673-699.
Aikenhead. G. S. (1988). An analysis of four ways of assessing student beliefs about STS topics. Journal of Research in Science Teaching, 25, 607-629.

Aikenhead, G. S., Fleming, R. W., \& Ryan, A. G. (1987).High-school graduates' beliefs about science-technology-society. I. Methods and issues in monitoring student views. Science Education, 71, 145-161.

Aikenhead, G. S., \& Ryan, A. G. (1992). The development of a new instrument: Views on science-technology-society (VOSTS). Science Education, 76, 477-491.

Aikenhead, G., Ryan, A., \&Desautels, J. (1989). Monitoring student views on sciencetechnology-society issues: The development of multiple-choice items. Paper presented at the annual meeting of the National Association for Research in Science Teaching, SanFrancisco,CA.

Akerson, V. L., Abd-El- Khalick, F., \& Lederman, N. G. (2000). Influence of a reflective explicit activity-based approach on elementary teachers' conceptions of NOS. Journal of Research in Science Teaching, 37(4), 295-317.

American Association for the Advancement of Science. (1989). Project 2061: Science for all Americans. New York: Oxford University Press.

American Association for the Advancement of Science. (1993). Benchmarks for science literacy: A Project 2061 report. New York: Oxford University Press.

An, Yu-La \& Kim, H.-J. (2011). Recognition of the Nature of Science by Preservice Teachers on the Basis of the Atomic Model. J. Korea Assoc. Sci. Edu. 31, 539-556.

Bauer, H. H. (1994). Scientific literacy and the myth of the scientific method. Champaign,IL:UniversityoftllinoisPress.

Billeh, V. Y., \&Hasan, O. E. (1975).Factors influencing teachers' gain in understanding the NOS. Journal of Research in Science Teaching, 12(3), 209-219.

Carey, S., Evans, R., Honda, M., Jay, E., \& Unger, C. (1989). An experiment is when you try it and see if it works: A study of grade 7 
students' understanding of the construction of scientific knowledge. International Journal of science Education, 11(Special issue), 514-529.

Cha, J. H., Kim, Y. H., \& Noh, T. H. (2004). Middle and High School Students' Views on the Scientific Model. Journal of the Korean Chemical Society, 48(6), 638-644.

Chandrasekhar, S. (1979). Beauty and the Quest for Beauty in Science. Physics Today, (July), 25-30.

Chen, S. (2006). Development of an instrument to assess views on NOS and attitudes toward teaching science (VOSE). ScienceEducation, 90, 803-819.

Clarke, B., \& Henderson, L. (2002). From Energy to Information: Representation in Science and Technology, Art, and Literature. PaloAlto, calif.StanfordUniversityPress.

Cooley, W., \&Klopfer, L. (1963). The evaluation of specific educational innovations. Journal of Research in Science Teaching, 1(1), 73-80.

Cotham, J., \& Smith, E. (1981). Development and validation of the conceptions of scientific theories test. Journal of Research in Science Teaching, 18, 387-396.

Creswell, J. W. (1994). Research design: Qualitative and quantitative approaches. Thousand Oaks, CA: Sage.

Elgin, C. Z. (2002). Creation as reconfiguration: art in the advancement of science. International Studies in the Philosophy of Science, 16(1), 1325.

Engler, G. (1990). Aesthetics in Science and in Art. The British Journal of Aesthetics, 30, 24-31.

Feyerabend, P. K. (1994). "Art as a Product of Nature as a Work of Art”. World Futures, 40, 87-100.

Gallagher, J. J. (1991). Prospective and Practice Secondary School Teacher's Knowledge and Beliefs about the Philosophy of Science. Science Education, 75, 121-133.

Hong. S. O. (2005). Science and Art : Some Preliminary Studies in their Convergence and Interfaces. Journal of Science and Technology
Studies, 5(1), 1-30.

Justi, R., \& Gilbert, J. (2000). History and philosophy of science through models: some challenges in the case of 'the atom'. International Journal of Science Education, 22, 993 - 1009 .

Kang, S. J., Scharmann, L. C., \& Noh, T. H. (2005).Examing Students' views on the NOS results from Korean 6th, 8th, and 10th graders. Science Education, 89(2), 314-334.

Kim, M. H. (1995). Comparison of science and art - with creative process. Scientific Thought, 13, 7-23.

Koulaidis, V., \&Ogborn, J. (1989). Scientific knowledge: Basic issues in the philosophy of science. Belmont, CA: Wadsworth Publishing Company.

Lederman, N. G. (1992). Students' and teachers' conceptions of the NOS: A review of the research. Journal of Research in Science Teaching, 29(4), 331-359.

Lederman, N. G., Abd-El-Khalick, F., Bell, R. L., \& Schwartz, R. S. (2002). Views of NOS questionnaire toward valid and meaningful assessment of learners' conceptions of NOS. Journal of Research in Science Teaching, 39, 497-521.

Lederman, N. G., Farber, P. L., Abd-ElKhalick, F., \& Bell, R. L. (1998). The Myth of the scientific method and slippery debates in the classroom: A response to McCreary. The Oregon Science Teacher, 39(4), 24-27.

Lederman, N. G., \& O’ Malley, M. (1990). Students' perceptions of tentativeness in science: Development, use, and sources of change. Science Education, 74, 225-239.

Liang,L. L., Chen, S., Chen, X., Kaya, O. N., Adams, A. D., Macklin, M., \& Ebenezer, J. (2008). Assessing preservice elementary teachers' views on the nature of scientific knowledge: A dual-response instrument.AsiaPacific Forum on Science Learning and Teaching, 9(1) Article, P.1.

Lim, J. H., Kang, S. M., Kong, Y. T., Choi, B. S., \& Nam, J. H. (2004). The Development of an 
Instrument to Assess High School Students' Views on Science-Technology-Society. Journal of the Korean Association for Science Education, 24(6), 1143-1157.

Lynch, M., \&Woolar, S. (1990). Representation in Scientific Practice. Cambridge, MA. MIT Press.

McAllister, J. W. (1996). Beauty and Revolution in Science. Ithaca, NY. Cornell University Press.

McComas, W., \& Olson, J. (1998).The NOS in international science education standards documents. In W. F. McComas (Ed.), The NOS in Science Education: Rationales and Strategies(pp. 41-52). Dordrecht, The Netherlands: Kluwer Academic Publishers.

Meichtry, Y. J. (1992). Influencing student understanding of the NOS: Data from a case curriculum development, Journal of Research in Science Teaching, 29, 389-407.

Mellado, V. (1997). Preservice teachers' classroom practice and their conceptions of the NOS. Science and Education, 6, 331-354.

Miller, A. I. (1995). Aesthetic, Representation and Creativity in Art and Science. Leonardo, 28, 185-192.

National Research Council.(1996). National science education standards. Washington, DC: National Academic Press.

National Science Teacher Association. (2000). NSTA position statement: The NOS. Document retrieved 3/18/03 http://www.nsta.org/.

Paik, S. H. (2006). The Problem of Explanation on Avogadro' s Hypothesis and Law Presented in Science Textbooks. Journal of the Korean Society for the Philosophy of Science, 9(2), 159184.

Rodríguez, M. A., \&Niaz, M. (2004). A Reconstruction of Structure of the Atom and Its Implications for General Physics Textbooks: A History and Philosophy of Science Perspective. Journal of Science Education and Technology, 13(3), 409-424.

Rubba, P. A., Schoneweg Bradford, C., \&Harkness, W. J. (1996).A new scoring procedure for the Views on Science-Technology-Society instrument. International Journal of Science Education, 18, 387-400.

Shapin, S. (1996). The scientific revolution. Chicago:TheUniversityofChicagopress.

Soh, W. J., Kim, B. K., \& Woo, J. O. (1998). Development of an Instrument to Assess Secondary School Students' Conceptions of the NOS.Journal of the Korean Association for Science Education, 18(2), 127 136.

Solomon, J., Duveen, J., \& Scot, L. (1994).Pupils' images of scientific epistemology. International Journal of Science Education, 16(3), 361-373.

Solomon, J., Scott, L., \&Duveen, J. (1996).Large-scale exploration of pupils' understanding of the NOS. Science Education, 80(5), 493-508.

Stent, G. S. (1982). "Prematurity and Uniqueness in Scientific Discovery”. In Scientific Genius and Creativity: Readings from Scientific American, 95-104. New York: Freeman.

Stent, G. S. (2001). "Meaning in Art and Science" in K. Pfenninger and V. Shubik Eds. The origins of Creativity, 31-42. Oxford: Oxford University Press.

Treagust, D. F., Chittleborough, G., \&Mamiala, T. L. (2002).Students' understanding of the role of scientific models in learning science. International Journal of Science Education, 24(4), 357-368.

Van Frassen, B. C. (1994). "Interpretation of Science; Science as Interpretation" in J. Hilgevoord eds. Physics and Our View of the World, 169-187. Cambridge: Cambridge University Press.

Welch, W. W., \& Pella, M. O. (1967-1968). The development of an instrument for inventorying knowledge of the processes of science.Journal of Research in Science Teaching, 5(1), 64.

Wilson, L. (1954). A study of opinions related to the NOS and its purpose in society. Science Education, 38, 159-164. 


\section{Appendix}

1. Do atomic model present actual atomic reality?

\begin{tabular}{l|l|l|lllll} 
& 5: Strongly agree & 4: Agree & 3: Neither agree nor disagree & 2: Disagree & 1: Strongly disagree \\
\hline \hline 1 Good model is the copy of reality, so atomic model presents actual atomic form. & 5 & 4 & 3 & 2 & 1 \\
\hline 2 & $\begin{array}{l}\text { Atomic model presents actual atomic form disclosed through experiment and } \\
\text { observation. }\end{array}$ & 5 & 4 & 3 & 2 & 1 \\
\hline 3 & $\begin{array}{l}\text { Atomic model similarly presents actual atomic form disclosed through experiment and } \\
\text { observation as closely as. }\end{array}$ & 5 & 4 & 3 & 2 & 1 \\
\hline 4 & Atomic model is made by reflecting on imagination and creativity of the scientists. & 5 & 4 & 3 & 2 & 1 \\
\hline 5 & $\begin{array}{l}\text { Atomic model is for not to express actual atomic form but to explain the experiment or } \\
\text { phenomena related to atomic structure. }\end{array}$ & 4 & 3 & 2 & 1 \\
\hline \hline
\end{tabular}

2. Atomic model finally became orbital model through many corrections and transformation processes. Is it possible to change this orbital model in the future?

\begin{tabular}{|l|l|l|l|l|}
\hline 5: Strongly agree & 4: Agree & 3: Neither agree nor disagree & 2: Disagree & 1: Strongly disagree \\
\hline
\end{tabular}

\begin{tabular}{lllllll}
\hline \hline $\begin{array}{l}1 \\
\text { Orbital model is very systematic and firm, so it is hardly change but can change in the } \\
\text { future. }\end{array}$ & 5 & 4 & 3 & 2 & 1 \\
\hline 2 & Orbital model will change easily like transformation process until now. & 5 & 4 & 3 & 2 & 1 \\
\hline 3 & $\begin{array}{l}\text { Because orbital model is proved as correct theory which explain related phenomena } \\
\text { very well, it will never be changed. }\end{array}$ & 5 & 4 & 3 & 2 & 1 \\
\hline 4 & Orbital model is accepted by most of the scientists so will not be changed. & 5 & 4 & 3 & 2 & 1 \\
\hline 5 & $\begin{array}{l}\text { Orbital model can be changed by interpreting scientific knowledge related to existing } \\
\text { atoms differently. }\end{array}$ & 5 & 4 & 3 & 2 & 1 \\
\hline 6 & $\begin{array}{l}\text { As developing technology and accumulating new scientific knowledge, orbital model is } \\
\text { subject to be changed. }\end{array}$ & 5 & 4 & 3 & 2 & 1 \\
\hline 7 & If orbital model is proved wrong, it certainly can be changed. & 5 & 4 & 2 & 1 \\
\hline \hline
\end{tabular}


3. After publishing Thomson's atomic model, Geiger and Marsden(1909) carried out the experiment of particlescattering. Then, Rutherford and Thomson acquired the same results respectively. Can they explain the same results by two different atomic models?

\begin{tabular}{|l|l|l|l|l|}
\hline 5: Strongly agree & 4: Agree & 3: Neither agree nor disagree & 2: Disagree & 1: Strongly disagree \\
\hline
\end{tabular}

The same results can be explained by only one atomic model, so they cannot explain
5 with two different atomic models.

Experienced scientists, Rutherford and Thomson, might interpret the result

2 objectively, excluding their subjectivity, so they cannot explain with two different $\begin{array}{llllll}5 & 4 & 3 & 2 & 1\end{array}$ atomic models.

Because of differences of two scientists' ability for performing research such as

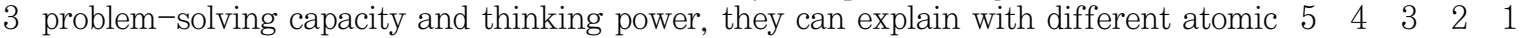
modelsby interpreting the same results differently.

Because of differences of two scientists' theoretic background and pre-knowledge,

4 they can explain with different atomic models by interpreting the same results $5 \begin{array}{lllll}5 & 4 & 3 & 2 & 1\end{array}$ differently.

5 Because of differences of two scientists' values and personal inclination, they can $\begin{array}{lllll}5 & 4 & 3 & 2 & 1\end{array}$ explain with different atomic models by interpreting the same results differently.

4. Thomson proved the existence of electrons, material consisting of atoms, through the cathode ray experiment. In this process, did Thomson use his imagination or inference?

\begin{tabular}{l|l|lllll} 
& 5: Strongly agree & 4: Agree & 3: Neither agree nor disagree & 2: Disagree & 1: Strongly disagree \\
\hline \hline $\begin{array}{l}\text { Thomson did not need to use his imagination or inference because he observed } \\
\text { electrons by his eyes through the experiment. }\end{array}$ & 5 & 4 & 3 & 2 & 1 \\
\hline 2 & Thomson might use logical and systematic inference. & 5 & 4 & 3 & 2 & 1 \\
\hline 3 & There might be a groundless jump of logic in Thomson' s inference. & 5 & 4 & 3 & 2 & 1 \\
\hline $4 \begin{array}{l}\text { Thomson did not use imagination because it cannot match with objective and logical } \\
\text { science research. }\end{array}$ & 5 & 4 & 3 & 2 & 1 \\
\hline 5 & $\begin{array}{l}\text { Using imagination reduces objectivity and reliability of science research. } \\
5\end{array}$ & 4 & 3 & 2 & 1 \\
\hline $\begin{array}{l}\text { Though using imagination will do better to limit in science research, Thomson might } \\
\text { use imagination inevitably. }\end{array}$ & 5 & 4 & 3 & 2 & 1 \\
\hline $7 \begin{array}{l}\text { Imagination is essential tool in performing science research, Thomson would use his } \\
\text { imagination naturally }\end{array}$ & 5 & 4 & 3 & 2 & 1 \\
\hline \hline
\end{tabular}




\section{$5-1$. How do scientists research?}

\begin{tabular}{|l|l|l|l|l|}
\hline 5: Strongly agree & 4: Agree & 3: Neither agree nor disagree & 2: Disagree & 1: Strongly disagree \\
\hline
\end{tabular}

1 There is universal scientific method used by scientists.

$\begin{array}{lllll}5 & 4 & 3 & 2 & 1\end{array}$

2 There is no universal scientific method used by scientists.

$\begin{array}{lllll}5 & 4 & 3 & 2 & 1\end{array}$

5-2. Thomson, Rutherford, and Bohr proposed their own atomic model after many research processes. How did Thomson, Rutherford, and Bohr research in this process?

3 All they followed universal scientific method.

$\begin{array}{lllll}5 & 4 & 3 & 2 & 1\end{array}$

4 Some of them followed universal method, the rest did not.

$\begin{array}{lllll}5 & 4 & 3 & 2 & 1\end{array}$

5 In their research processes, they would use various methods, but for verifying and determining their results, at last, they followed universal scientific method.

$\begin{array}{lllll}5 & 4 & 3 & 2 & 1\end{array}$

There is no universal scientific method, so they all used unique and appropriate research method.

6. The following picture express happy heart of woman sitting on the chair by the brilliant primary colors by Picasso. Generally, people think Picasso's work as art but Bohr's atomic model as science. What are the similarity and difference between Picasso's work and Bohr's atomic model?

5: Strongly agree 4: Agree 3: Neither agree nor disagree

2: Disagree 1: Strongly disagree

1 Bohr' s atomic model is 'discovering' atomic reality in nature, but Picasso' s work is $\begin{array}{rlllll}5 & 4 & 3 & 2 & 1\end{array}$ 'creating' as nature of the human inner world.

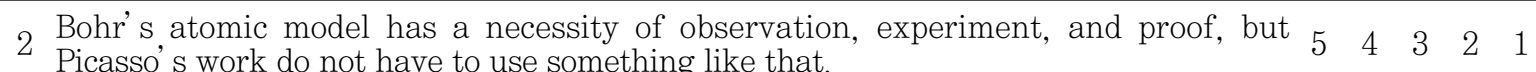

3 Both Bohr's atomic model and Picasso' s work include imagination and creativity as $\begin{array}{lllll}5 & 4 & 3 & 2 & 1\end{array}$ very important factors. own way of explaining and interpreting nature.

5 Bohr's atomic model can be discovered by other scientists, but Picasso is the only $\begin{array}{lllll}5 & 4 & 3 & 2 & 1\end{array}$ person who can draw his work.

6 Picasso's work pursues aesthetics, but Bohr's atomic model is not relevant to $\begin{array}{ccccc}5 & 4 & 3 & 2 & 1\end{array}$ aesthetics. 